\title{
บusisersaly
}

\section{Perceptions of the unregistered healthcare worker's role in pre-registration student nurses' clinical training}

Hasson, F., McKenna, H., \& Keeney, S. (2012). Perceptions of the unregistered healthcare worker's role in preregistration student nurses' clinical training. Journal of Advanced Nursing, 00. https://doi.org/10.1111/jan.12023

Link to publication record in Ulster University Research Portal

\section{Published in:}

Journal of Advanced Nursing

Publication Status:

Published (in print/issue): 01/01/2012

DOI:

10.1111/jan.12023

\section{Document Version}

Author Accepted version

\section{General rights}

Copyright for the publications made accessible via Ulster University's Research Portal is retained by the author(s) and / or other copyright owners and it is a condition of accessing these publications that users recognise and abide by the legal requirements associated with these rights.

\section{Take down policy}

The Research Portal is Ulster University's institutional repository that provides access to Ulster's research outputs. Every effort has been made to ensure that content in the Research Portal does not infringe any person's rights, or applicable UK laws. If you discover content in the Research Portal that you believe breaches copyright or violates any law, please contact pure-support@ulster.ac.uk. 


\title{
ORIGINAL RESEARCH
}

\section{Perceptions of the unregistered healthcare worker's role in pre-registration student nurses' clinical training}

\author{
Felicity Hasson, Hugh P. McKenna \& Sinead Keeney
}

Accepted for publication 1 September 2012

Correspondence to Felicity Hasson: e-mail: f.hasson@ulster.ac.uk

Felicity Hasson BA MSc PGDip Senior Lecturer

School of Nursing, Institute of Nursing

Research, University of Ulster,

Newtownabbey, UK

Hugh P. McKenna CBE PhD RGN Professor, Pro Vice Chancellor Research and Innovation, University of Ulster, Newtownabbey, Belfast, UK

Sinead Keeney BA MRes PhD Senior Lecturer

School of Nursing, Institute of Nursing Research, University of Ulster, Newtownabbey, UK
HASSON F., MCKENNA H.P. \& KEENEY S. (2012) Perceptions of the unregistered healthcare worker's role in pre-registration student nurses' clinical training. Journal of Advanced Nursing 00(0), 000-000. doi: 10.1111/jan.12023

\begin{abstract}
Aim. To explore the unregistered healthcare worker's role and influence on student nurses' clinical learning experience.

Background. Across the developed world, the role of the unregistered worker is exceeding its traditional boundaries. Evidence suggests that this includes the dayto-day mentoring of pre-registration student nurses. However, no research to date has explored reasons as to why this is occurring, what types of tasks are taught, and the consequence of this.

Design. A sequential exploratory mixed method research design was adopted.

Method. Reporting on the final qualitative phase of a mixed method sequential research study, semi-structured interviews were undertaken with 59 unregistered healthcare workers across four hospitals in Northern Ireland. Transcriptions were analysed using a content analysis approach; all data were collected in 2010.

Results. Findings show the diversity of the unregistered healthcare workers' roles and confirm that they play a major part in the education of student nurses with regards to basic, clinical, and non-clinical tasks, with and without the approval of registered staff. However, their involvement did not reflect their levels of expertise as evidenced by certified training. Their participation was justified based on mentor unavailability, their closeness to the student and the patient. While some did raise concerns, they recommended that these workers be formally involved in nurse education.

Conclusion. Mechanisms of workforce planning need to pay particular attention to the expanding role of unregistered healthcare workers as 'role drift' has the potential to alter patterns of work and affect current educational approaches impacting on the acquisition of clinical skills. Further research is recommended in this domain.
\end{abstract}

Keywords: clinical practice, clinical training, Health Care Assistants, mixed methods, nurses, nursing, nursing auxiliaries, nursing students, pre-registration 


\section{Introduction}

The unregistered healthcare worker is a common feature across some national and international healthcare systems. Although no definitive title exists to describe this role, the primary remit of the role is to assist in the delivery of care under the direction and supervision of a registered professional. In the United States, there are up to 65 different designations (Wurstner \& Koch 1995); however, the predominant title used is nursing assistive personnel (NAP) (American Nurses Association 2007). In Europe, the titles range from 'aide- soignant' (nurse's aide) in France (Arborio 2004), to nursing assistant in Norway (Dahle 2003). In the UK, it is estimated that there are over 300 titles (Spilsbury \& Meyer 2004), however, the label Healthcare Assistant (HCA) and Nursing Auxiliary (NA) are commonly applied (Department of Health (2004) and for the purpose of this paper the term HCA has been adopted. In the National Health Service (NHS) most jobs are paid according to the Agenda for Change pay bands (Department of Health 2004), which range from 1-9. HCA and NA roles are generally paid band 2 and 3 salaries.

In the UK, HCAs represent an estimated $15 \%$ of the healthcare workforce (National Guidance Research Forum 2006). Whilst support for regulation exists (Unison 2008, Hand 2012) at present the role is non-regulated. Various steps have been taken to rectify this, for example the Department of Health has commissioned Skills for Health and Skills for Care to develop national minimum training standards and a code of conduct for England, the results of which are due by the end of 2012 (Pond 2012). In the UK, National Vocational Qualifications (NVQs) from level 1 (basic) - 5 (advanced) in healthcare have been developed based on statements of competence relating to employment (Behrens 2003). However, although nationally recognized, there is no mandatory requirement for HCAs to have any level of NVQ award (Spilsbury et al. 2009, Wakefield et al. 2009). Therefore, the role is not currently systematically underpinned by training or education to any national standard.

Research into the HCA role remains scant, yet reports have presented a demographic profile reflecting a group of mature and experienced workers with vast care experience (Thornley 2000, Kessler et al. 2010). Traditional tasks include direct patient care and other non-nursing activities such as cleaning, stocktaking, and clerical work (Thornley 2000, Bridges et al. 2003, Spilsbury \& Meyer 2004, Knibbs et al. 2006). In the absence of any UK wide agreed standards, the nature of the role depends on workplace demands, staff ideologies, and the model of nursing workforce employed (Workman 1996, Bach et al. 2005, Spilsbury \& Meyer 2005, Hancock \& Campbell 2006). This has resulted in the role being multifaceted and diverse.

It is acknowledged that HCAs are responsible for the fundamentals of patient care (Unison 2010), often working alone with little or no access to supervision, undertaking tasks that are in the registered nurses' (RNs') remit (Thornley 1997, 1998, Bridges et al. 2003, McKenna et al.2004, Hancock et al. 2005, Spilsbury \& Meyer 2005, Butler-Williams et al. 2010, Kessler et al. 2010). Commonly undertaken tasks include, administering drugs, monitoring blood glucose levels, and running clinics while unsupervised (Thornley 2000, Spilsbury \& Meyer 2005). Another example is their role in helping to train (albeit unofficially) student nurses who are on clinical placement (Melia 1981, Thornley 2000, O'Driscoll et al. 2010). Paradoxically, standards of mentoring in pre-registration nursing do not acknowledge the input that the HCA has in supporting students (Nursing and Midwifery Council (2004). Whilst it is recognized that the majority of research in this area stems from work undertaken on adult nursing in the UK, no research to date has explored the extent and effect to which this occurs nationally or internationally. This is despite the fact that many healthcare systems employ similar assistant roles which students may come into contact with during clinical learning.

This study aimed to gain an insight into the HCAs role and their experiences in student nurse training. This was part of a larger mixed methods study where the views of students with regard to HCAs were investigated.

\section{Background}

In the UK, the NMC standards of proficiency for pre-registration nursing education require students to spend $50 \%$ of their programme on clinical placement (Nursing \& Midwifery Council 2010). During clinical placement, RNs are assigned to students as mentors who are responsible for ensuring that standards of proficiency are attained (Nursing \& Midwifery Council 2010). However, research exploring the roles of HCAs (Thornley 1998, 2000, Duffin 2001, Spilsbury \& Meyer 2004); RNs (Kessler et al. 2010), nurse educators (Allan et al. 2008, Allan \& Smith 2009), and students (O'Driscoll et al. 2010) confirm that HCAs are also playing a role in students' clinical practice.

Opinions are divided with regard to the involvement of HCAs in nursing education (Waters 1999, Harrison 2006). Despite disagreement, several informal training programmes have been developed to help educate HCAs about nurse training and their role (Yellott 2003, Wright 2006), which 
essentially acknowledges the role they play in supporting and facilitating student nurses.

Several possible explanations for HCA involvement in student nurse training have been cited in the literature including lack of leadership, student fears and role overlap. Since 2010 the NMC no longer require a student to be attached to one mentor, instead a mentor must be available $40 \%$ of the time and recognize that other healthcare professionals can play a role in this process. Nevertheless, evidence suggests that mentors are often unavailable, due in part to heavy workloads, large student intakes and staff shortages (Donaldson \& Catrer 2005, McGowan 2006, Pearcey 2008, O’Driscoll et al. 2010). Evidence suggests when mentors were not available, nursing students were left to work with HCA staff (Melia 1981, Burkey 1984, LloydJones et al. 2001) or doing HCA work (Cahill 1996, Neary et al. 1996, Gray \& Smith 1999, Lloyd-Jones et al. 2001, McGowan 2004). This led to nursing skills being 'picked up' from HCAs, influencing the students' learning experience and subsequent professional development (Lloyd-Jones et al. 2001).

The idea that student nurses may take responsibility for their own learning and actively seek out and learn from HCAs in the clinical setting has also been suggested by students (Creek 2003, Gibbs 2003, Kirk \& Keynes 2003), academics (Glen \& Clark 1999), clinical placement co-ordinators (Yellott 2003), and HCAs (Slaughter 2007). Studies have demonstrated that students fear approaching registered staff for help in case they are refused or are perceived as imposing or annoying staff (Higgins \& McCarthy 2005). Therefore, students have been found to develop close working relationships with HCAs (Spilsbury \& Meyer 2004) and learn the basic care skills from this more approachable and less threatening group.

Research suggests that HCAs have replaced nurses in delivering patient care (Kessler et al. 2010) and believe their 'hands on' knowledge and role is more important than that of RNs (Lee-Treweek 2003). Researchers have noticed little difference between the roles (Workman 1996) except in relation to administration of medicines and dealing with paperwork (Thornley 2000, Kessler et al. 2008). A direct consequence is that students are reported to be confused as to whom they should learn from and what they need to learn (Ousey 2006). There is evidence that they are learning the fundamental skills by observing and working with HCAs in practice (O'Connor 2007, Cowie et al. 2008). Both O'Driscoll et al. (2010) and Mackintosh (2006) warn that this may result in direct care being viewed as within the HCA remit and hence of less importance.
Despite the growing acknowledgement that HCAs play a role in students nurses' clinical learning, knowledge about the extent and reasons for involvement is an under researched area. This article reports on a final phase of a large mixed methods project that explored the skills HCAs teach nursing students and the reasons for this.

\section{The study}

\section{Aim}

The aim of this study was to explore the HCA's role in student nurses' clinical learning.

\section{Design}

The findings were taken from a large multi-method sequential exploratory research project which explored how the interactions of HCAs with adult student nurses relate to and impact on the latter's clinical learning experience. The research was conducted in three phases and was guided by the symbolic interactionist framework (Mead 1934, Blumer 1969). The first stage comprised interviews and focus groups undertaken with 45 pre-registration nursing students to explore experiences and views on the role of the HCA in their learning experience. In the second stage, a questionnaire, built on the interview data, was disseminated to 460 pre-registration nursing students to confirm and explore further details of HCA involvement in clinical teaching. The third and final stage involved semi-structured interviews with 111 HCAs based on the NHS and independent nursing home sector. Interview schedules were based on a review of the literature and from previous stages of the research. This enabled previous findings to be confirmed and additional issues from the HCA's perspective to emerge. This article reports on the interviews conducted with HCAs $(n=59)$ employed in four major acute NHS hospitals in Northern Ireland, during the third and final stage of the research. It discusses how HCA perceive their role and the extent of their influence on students' clinical learning.

\section{Sample/participants}

Semi-structured interviews were undertaken with a purposive sample of HCAs. Purposive sampling was used to ensure that those respondents who have had exposure working alongside student nurses were selected. Criteria for inclusion required HCAs to be currently working in medical, surgical, accident and emergency, outpatients, 
intensive care (or coronary care), maternity and gynaecology departments. These clinical areas were included because they accept adult pre-registration nursing students for placement experience. Participants needed to meet the inclusion criteria which included HCAs who had direct contact with patients, had experience of working alongside pre-registration adult branch nursing students, were over the age of 18 , and provided written consent.

To aid recruitment to the study, several strategies were adopted. These included recruitment posters and meetings with ward managers informing them of the study and asking them to issue a letter of invitation to HCAs. Recruitment posters were also displayed and presentations given at two Royal College of Nursing events. Both the recruitment letter and letter of invitation informed participants that if they were interested in taking part they should contact the researcher. The participant was not subject to any time pressure to make this decision.

Once a potential participant contacted the researcher, the study was explained, inclusion criteria outlined and any questions answered. Once verbal agreement was obtained, contact details were recorded and an information pack containing a cover letter, information sheet, and consent form (with stamped addresses envelope) was issued. On receipt of the completed consent form, participants were contacted by the researcher to arrange a convenient time and location for the interview to take place.

\section{Data collection}

In total, 59 HCAs took part in the study. All interviews were undertaken by one author $(\mathrm{FH})$ in NHS premises, lasting between 40-90 minutes and were undertaken in 2010. A semistructured interview schedule, based on the results of previous research stages (student interviews and questionnaire) and relevant literature, was used to elicit information (Table 1). At the end of the interview, HCAs were also given the opportunity to discuss other issues related to their role. Participants were asked to recount their experiences of working alongside student nurses and in particular their interactions with and views about student nurses. The interview schedule was open ended so as to explore variations in participants' experiences. Probes were used to clarify the meanings of responses. To enable the researcher to describe the characteristics of those who took part, each participant completed a tick box questionnaire at the end of the interview. With permission, all the interviews were audio taped and transcribed verbatim.

\section{Ethical considerations}

Ethics approval was received from the University where the research was undertaken and from the National Research
Table 1 Interview schedule/topic guide with examples of questions.

Role of the Healthcare Assistant

Could you outline what your role is in the ward setting?

Knowledge of student nurse training

Have you been told about the role of the student nurse on

placement? (Probe: If so, what have you been told and by whom?

If not, what would you like to know?)

Work structure of the HCA and Student Nurse

Has a registered ward member of staff ever officially allocated a student nurse to work alongside you? (Probe: If so, how do you feel about this? Could you outline a recent example of when this occurred? Where you supervised by a registered member of staff whilst working with the student nurse?)

HCA role in student training

Do you think HCAs could play a role in student nurse training?

(Probe: If yes, what do you think this role could be? If no, why?)

Role perceptions: HCA, Student Nurse and RNs

Do you think there are similarities between the HCA and student nurses role? (Probe: If, yes what are these similarities? If not, why do you think there are no similarities?)

Working relationship between the HCA and Student Nurse

What do think are the main challenges (if any) facing HCAs who work alongside student nurses?

Impact of HCA and Student Nurse Role

What impact do you think HCAs have on student nurses learning? (Probe: please explain your answer)

Other Comments

Ethics Service. Informed consent was obtained from each participant.

\section{Data analysis}

Inductive content analysis was performed. Transcripts were analysed using Miles and Huberman (1994) framework. Analysis involved three main steps, data reduction, display and conclusion, and verification process. Codes were attached to the data that represented shared meanings and were grouped to identify overarching and subthemes. For example, a major theme 'justification for HCA involvement' incorporates some subthemes relating to the perceptions of the role of the mentor, HCA, and student. The data collected from the demographic questionnaire were entered into SPSS (version 17), which was used to describe the characteristics of participants.

\section{Validity and reliability/rigour}

Measures to ensure trustworthiness of the data were implemented (Lincoln \& Guba 1985, Patton 1987, Polit \& Hungler 1999). Credibility was assured by the use of participants' descriptions of their own experiences. Transferability was 
demonstrated by dense description of research design, analysis, and findings. Confirmability and dependability was enhanced by the researcher detailing any influence on the data and by two researchers (SK \& HMcK) examining the process and outcomes of the study, which involved reviewing transcripts.

\section{Results}

\section{Characteristics of participants}

Most participants were women $(86.4 \% n=51)$ and while job titles ranged the most common label was Nursing Auxiliary (64.4\% $n=38)$. The majority of respondents interviewed were pay grade Band 2, with most having accumulated over 10 years work experience. The characteristics of the participants are shown in Table 2. From analysis of the transcripts four key themes were identified including, close working relationship, role in student learning, approach to teaching, and justification and consequences for involvement.

\section{Close working relationship}

All the participants confirmed that whilst on placement student nurses worked alongside them to deliver patient care. This was mainly due to mentor and/or staff unavailability. This was also in response to RNs allocating the student nurse to work alongside HCAs or to students themselves making the decision to 'tag along' whilst HCAs performed their duties. This was viewed as a daily occurrence for HCAs and they accepted it without question as normal practice:

They could be paired off in the morning with you.....they [registered staff member] could say [to the student] in the morning 'could you team with [assistant's name] for the morning and then you know your lead nurse or whatever nurse is looking after you will take over then. (Res No 13 Surgical, Band 2, NVQ 3)

The majority of participants claimed that most or all of their work was unsupervised and this was no different when working with students. Most accepted this without question, or on reflection some did regard this has having a potentially significant impact on patient care, standards of education and training, and inter-personal relationships with students.

\section{Role in student learning}

Over half the sample initially stated that they did not play a role in teaching students; however, as the interviews
Table 2 Participants socio-demographic characteristics.

\begin{tabular}{|c|c|c|c|}
\hline Characteristic & Category & Value & Percentage \\
\hline \multirow[t]{2}{*}{ Gender } & Male & 8 & $13 \cdot 6 \%$ \\
\hline & Female & 51 & $86 \cdot 4 \%$ \\
\hline \multirow[t]{5}{*}{ Age } & $18-24$ & 1 & $1.7 \%$ \\
\hline & $25-34$ & 7 & $11 \cdot 9 \%$ \\
\hline & $35-44$ & 19 & $32.2 \%$ \\
\hline & $45-54$ & 22 & $37 \cdot 3 \%$ \\
\hline & $55-65$ & 10 & $16 \cdot 9 \%$ \\
\hline \multirow[t]{4}{*}{ Job Title } & $\begin{array}{l}\text { Nursing } \\
\text { Auxiliary (NA) }\end{array}$ & 38 & $64.4 \%$ \\
\hline & $\begin{array}{l}\text { Healthcare } \\
\text { Assistant (HCA) }\end{array}$ & 8 & $13 \cdot 6 \%$ \\
\hline & $\begin{array}{l}\text { Acute Support } \\
\text { Nurse (ASN) }\end{array}$ & 6 & $10 \cdot 2 \%$ \\
\hline & $\begin{array}{l}\text { Support } \\
\text { Worker (SW) }\end{array}$ & 7 & $11.9 \%$ \\
\hline \multirow[t]{2}{*}{ Band grade } & Band 2 & 36 & $61 \%$ \\
\hline & Band 3 & 23 & $39 \%$ \\
\hline \multirow[t]{7}{*}{ Clinical site } & Medical & 12 & $22 \%$ \\
\hline & Surgical & 11 & $18 \cdot 6 \%$ \\
\hline & $\mathrm{A} \& \mathrm{E}$ & 8 & $13 \cdot 6 \%$ \\
\hline & $\begin{array}{l}\text { Outpatients } \\
\text { department }\end{array}$ & 8 & $13 \cdot 6 \%$ \\
\hline & Intensive care & 2 & $3.4 \%$ \\
\hline & Coronary care & 5 & $8.5 \%$ \\
\hline & $\begin{array}{l}\text { Maternity and } \\
\text { Gynaecology }\end{array}$ & 12 & $20 \cdot 3 \%$ \\
\hline \multirow{6}{*}{$\begin{array}{l}\text { Length of HCA } \\
\text { work experience }\end{array}$} & 1 year & 1 & $1.7 \%$ \\
\hline & $2-3$ years & 1 & $1.7 \%$ \\
\hline & $4-5$ years & 7 & $11 \cdot 9 \%$ \\
\hline & $6-7$ years & 10 & $16 \cdot 9 \%$ \\
\hline & $8-9$ years & 3 & $5 \cdot 1 \%$ \\
\hline & 10 years plus & 37 & $62 \cdot 7 \%$ \\
\hline \multirow[t]{2}{*}{ VQ Level 2} & Yes & 39 & $66 \cdot 1 \%$ \\
\hline & No & 20 & $33.9 \%$ \\
\hline \multirow[t]{2}{*}{ NVQ Level 3} & Yes & 16 & $27 \cdot 1 \%$ \\
\hline & No & 43 & $72 \cdot 9 \%$ \\
\hline
\end{tabular}

progressed participants revealed that they either unofficially or informally did so. Others stated that in addition to their normal duties, they were being asked by RNs to advise, coach, and help teach nursing students. This role was adopted despite the fact that HCAs were not trained in the principles or practice of student learning as stated:

First year students, I haven't a notion what they have to learn; management students that we have on the ward- now I have a fair idea what they do, well that is all, I wouldn't say any other year, second years or first years I wouldn't know what they are here to learn. (Res No 10, Medical, Band 2, no NVQs)

Most participants assumed a difference in the learning needs across the students' years, believing that first years needed to be taught patient care, second years required a 
mixture of patient care and growing competence in more nursing orientated tasks. Third years, however, were recognized as requiring the input from registered staff to learn about the management of the ward.

Regardless of band grade or the level of NVQ qualification attained, participants identified a range of tasks that they taught student nurses. The types of tasks varied according to clinical setting and individual preferences. The most common tasks related to direct care that were most visible to patients such as bed making, bathing, toileting, dressing, hygiene, and care of the patient, manual handling (positioning and mobilizing), caring for the patients' environment and property, feeding, escorting to other departments, and supporting and monitoring patients. They were also involved in teaching a range of other tasks such as stock taking, making appointments, preparing and maintaining environments, infection control, defining policy procedures such as reporting accidents, liaising with other professionals, and ward roles. HCAs in this study also reported teaching students a range of technical tasks that were traditionally undertaken by RNs (Table 3 ).

\section{Approach to teaching}

Most participants in this study were critical of current approaches to nurse education, believing that there was too much emphasis on academic instruction, with limited time spent in practice caring for patients. The importance of gaining hands on care experience was perceived by HCAs to be of high value, as they believed this was the essence of nursing:

What I would probably say is see these two hands, they have got 10 years' experience, you could sit in University and do that.... but this is what a stoma looks like in a book and then when they see it first hand, it is quite a shock to them. (Res No 32, Surgical, Band 2, NVQ 2)

When questioned about the approach they adopted to training, they revealed that it reflected how they themselves gained most of their knowledge, through observing and engaging with other registered and unregistered staff. Consciously and subconsciously they engaged in a variety of teaching strategies such as instructional methods, skills demonstrations, question and answer periods, spoken direction, and active participation. Some revealed that they also adopted an informal method of assessment to ensure that students were competent in undertaking the skill before being allowed to practice it themselves. This involved the one-to-one teaching of patient skills involving direct observation of the student. This resulted in the HCA mak-
Table 3 Tasks taught by clinical setting.

\begin{tabular}{|c|c|}
\hline Clinical setting & Tasks taught \\
\hline$A \& E$ & $\begin{array}{l}\text { Wound and dressing care, monitoring } \\
\text { diagnostic machines, setting up for } \\
\text { procedures, systemic observations, } \\
\text { electrocardiogram tracings, liaising with } \\
\text { medical and other staff, testing samples, } \\
\text { relating medical information to relatives, } \\
\text { plaster casts, oxygen machines, mouth } \\
\text { suction and mortuary duties }\end{array}$ \\
\hline Coronary care & $\begin{array}{l}\text { Observing and recording the condition of } \\
\text { patients and maintaining patient records }\end{array}$ \\
\hline Medical & $\begin{array}{l}\text { Observing and recording the condition of } \\
\text { patients, wound and dressing care, } \\
\text { Glucose monitoring machines for } \\
\text { detection and assessment of diabetes, } \\
\text { urinalysis, skin care, advocating on } \\
\text { behalf of patients, provision of } \\
\text { emotional support for patients and } \\
\text { last offices }\end{array}$ \\
\hline Outpatients & $\begin{array}{l}\text { Observe and record the condition of } \\
\text { patients, running clinics, measure and } \\
\text { record height and weight urinalysis and } \\
\text { preparation of specimens, blood pressure } \\
\text { and temperature, taking blood samples, } \\
\text { giving injections, setting up clinics, } \\
\text { reading and reporting readings and } \\
\text { procedure to send samples to the } \\
\text { laboratory }\end{array}$ \\
\hline Maternity/Gynaecology & $\begin{array}{l}\text { Educating mothers about breastfeeding } \\
\text { and caring for baby, venepuncture, baby } \\
\text { bath, bed bath, monitoring pulse, blood } \\
\text { pressure and temperature, changing } \\
\text { newborns, feeding babies/bottle } \\
\text { demonstrations, urinalysis and } \\
\text { preparation of specimens, catheter care, } \\
\text { intravenous cannula care, last offices, } \\
\text { and maintaining patient dignity. }\end{array}$ \\
\hline Surgical & $\begin{array}{l}\text { Manual handling equipment, } \\
\text { disconnecting IV lines, blood monitoring } \\
\text { for people with diabetes, Urinalysis, } \\
\text { stoma care, caring for amputations, and } \\
\text { preparing students for the reality of } \\
\text { amputations, wound and dressing care, } \\
\text { NG feeds, and electrocardiogram } \\
\text { tracings electrocardiogram tracings. }\end{array}$ \\
\hline $\mathrm{ICU}$ & Ventilator set up \\
\hline
\end{tabular}

ing judgments about whether competency had been achieved. This also provided the HCA with the opportunity to provide the student with feedback:

Yes, I would show the student, the ECG. I would show them where the stickers and the leads all go to, stick them on the skin. I would let them do it and put the leads on the bodies and I would make 
sure everything is in the right place. It's just to make sure it's done properly. (Res No 16 A\&E, Band 2 NVQ2).

It is interesting to note that only a handful of participants reminded students to check with their RN mentor if they had any further questions or if they were still unsure how to perform the skill.

\section{Justification and consequences}

In addition to mentor unavailability, several other possible justifications for HCAs' involvement in student nurse learning were provided. First, as most of the HCAs' responsibilities were focused on the provision of direct patient care, this was viewed as the key justification as to why they should teach and be involved in student learning. Some HCAs disclosed that RNs in their clinical area were not involved and were perceived to be uninterested in the daily delivery of patient care; therefore they were confident that their hands on knowledge and their spectrum of experiences equipped them to be better placed to teach such skills. Participants viewed their role to be very similar to the role of the RN. This led many to differentiate the roles solely on the administration of medication and paperwork.

Second, mentors and nurses were viewed as being too busy to supervise and teach; therefore HCAs intervened to help out. This is despite the fact that some performed and taught tasks without the necessary skills and competence to do to and in doing so they exceeded their job boundary. Only a handful of HCAs had concerns about undertaking or being asked to perform tasks they were not trained to do. In addition, a few believed that some registered staff members' attitude towards students training needs differed according to the year of study, leading to further justification for HCA involvement:

You do find that trained staff just doesn't want to be bothered with first and second years. It's not that they don't want to be bothered it's just to them they are an auxiliary. Third year students they start to take, she has responsibility to take down 6 months before she is qualified, she has to be able to run a ward and they are starting to get really into that, pushing them towards that. So you do find the 1 st and 2 nd years are more involved with the auxiliaries. (Res No 31 Medical, Band 2 NVQ 2)

Third, the erosion of the traditional nurse's role has resulted in HCAs not only becoming closer to the patient but also to the student nurse. HCAs believed that their role overlapped with the student nurse in the course of their training and this was confirmed by the close working relationship they had. As a consequence, HCAs supported students emotionally and practically on placement and believed they should be involved formally in coaching and advising student nurses, especially first year students:

Because at the end of the day if they can't do this job [assistants] they are never going to be able to be a nurse, no way. (Res No 55 Coronary Care, Band 3 NVQ $2 \& 3$ )

I think they would learn more if they came along with the like of me. A student nurse coming with me will learn more with me in minor injuries than she will with a staff nurse, left with a staff nurse that is too busy. (Res No 12 A\&E, Band 2, NVQ 2)

A final reason for HCA involvement was their awareness that some students were afraid or more reluctant to approach their mentors or staff nurses. Therefore, students would approach HCAs for guidance. HCAs believed they were more approachable than staff nurses and many stated that they identified and treated students like his/her own child and were therefore protective of them, wanting to help them to succeed:

I know I feel sort of like a mummy to some of them you know, what age they are but they would come and ask questions I am quite comfortable to do so you know. (Res No 15, A\&E, Band 2, NVQ2)

From the rationales provided there were several implications for the HCAs' role, including recognition that an HCA can only teach students to a certain level, acknowledgement that this is an unofficial extension of their role, for which they are not recognized or financially rewarded and concerns about the impact of their input on education standards. A few participants also revealed the benefits of working alongside students such as HCAs gaining an insight into theory and up-to-date nursing knowledge from students.

\section{Discussion}

The socio-demographics of participants in this study reflect that of other studies reported in the literature (Thornley 2000, Kessler et al. 2010). The majority were mature females with previous caring experience, operating under a diversity of titles. Whilst patient care duties remain at the core of their responsibility they were also involved in the delivery of technical and specialist tasks. This highlighted their extended role and corroborated previous research (Thornley 2000, McKenna et al. 2004, Spilsbury \& Meyer 2004, Knibbs et al. 2006, Kessler et al. 2010). This study 
has also confirmed previous research indicating that HCAs are working closely with and are intrinsically involved in nursing students training, regardless of educational attainment (Melia 1981, Thornley 2000, Duffin 2001, Spilsbury \& Meyer 2004, Allan et al. 2008, Allan \& Smith 2009, Ousey 2009, Kessler et al. 2010, O'Driscoll et al. 2010). Not only are they involved in teaching basic technical tasks (Kessler et al. 2010, O'Driscoll et al. 2010) but they claim to have taught an array of patient care, non-nursing, technical, and specialized tasks. Working with and teaching a student was reported to be a normal occurrence undertaken largely in an unsupervised capacity.

The delegation of teaching responsibilities occurred in two ways, either formally under the directive of RNs or informally as a result of the unseen close working relationship between the student and the HCA. Whilst this may be what Allan and Smith (2009) referred to as students taking control of their own learning, it also limits learning experiences to those within the HCAs' remit. This is also an example of the hidden or partially realized extension of the HCAs' role, which Thornley (2000) and Kessler et al. (2010) warned masks the true encroachment of the role in practice. It may be assumed that heavy workloads, staff shortages, and balancing students learning needs with service demands may have resulted in registered staff accepting the delegation of teaching to HCAs for the sake of maintaining the quality of services provided.

It may also highlight the flexibility and diversity of the HCA role, which stems from ongoing assumptions of what is and what is not nursing. If one accepts that HCAs are delivering the majority of patient care, should they be teaching such skills and not the RN? Where then does the line be drawn, as the HCA role is also involved and responsible for a range of specialized and technical tasks? If one accepts this argument, it not only makes the extension of their role more professionally acceptable but has the potential to lead to greater blurring of roles.

Regardless of how students come to work with and learn from HCAs, it has a bearing on the professional development of the HCAs, RNs, and the students. Whilst arguments and initiatives highlighting the inclusive approach to learning have been made (Thornley 1997, Yellott 2003, Wright 2006), for an HCA, this extends the boundaries of their role and results in them being used inappropriately. In this study, having received no preparation for their extended role, HCAs relied on their own experiences of how they themselves learned, with many not realizing the full impact they had on the transfer of knowledge and skills to students. From a student perspective, working with and learning from HCAs has the potential for students to feel undervalued, for stifling learning opportunities and, as Mackintosh (2006) warned, see certain tasks and skills as being within the HCAs' remit. Moreover, whilst HCAs may be proficient in undertaking a task, it is unclear if they understand the rationale or theory underpinning it (Pearcey 2000). Ultimately there is a danger that students conform to outmoded or poor practice at the expense of providing quality care. Conflicting opinion about the function HCAs should serve and ongoing sentiments in the literature that HCAs are taking over the nurses' role (Pearcey 2008) has the potential to result in disillusionment and tension in the nursing profession. Considering this evidence and the claim that education is not preparing students for practice (United Kingdom Central Council 1999, Mulholland 2003, Institute of Medicine 2010) and that students learn from unqualified and unregulated staff has the potential to raise further disquiet.

\section{Limitations}

Like all studies, this study has several limitations. It is recognized that whilst interviews can help enhance validity and give the opportunity to probe and seek clarification, the effect of being involved in the interview may alter the views and/or perceptions of the participants (Tod 2006). It is also acknowledged that expressed attitudes may not be an indicator of the respondents' actual behaviour and that interview questions used were based on participant's memories, which can also be inaccurate. However, interviews allowed for views and experiences to be probed, emotions to be interpreted, and comparable qualitative data to be collected (Gerrish \& Lacey 2010).

The study did not involve mentors or RNs' perspectives. It is recognized that obtaining such views would have provided a broader perspective of what is occurring and may be notably different from the opinions of HCAs reported in this study. The study was also limited by a small sample and subject to response and sample bias as it is recognized that those who consented to be interviewed may not be representative. Moreover, findings expressed include only the HCA opinion of what training they see and do not recognize that RNs may have been separately supporting and assessing students in practice which may not be seen or appreciated by the HCAs.

Further the views of HCAs working in adult branch nursing students explored that the role of the HCA in mental health and paediatric nursing areas may differ substantially. Despite these limitations, the results have suggested that HCAs have a major role in influencing the clinical learning of student nurses. 


\section{What is already known about this topic?}

- The unregistered healthcare worker, referred to as a Healthcare Assistant, plays a central role in the delivery of patient care yet often encroaches on the professional remit of the registered nurse.

- The literature suggests that students are working more closely with Healthcare Assistants than with registered nurses and that Healthcare Assistants are playing a role in advising and coaching students in clinical placement.

- However, there has been scant in-depth attention paid to the role in student nurses' clinical learning experience.

\section{What this paper adds}

- This research confirms that regardless of their educational attainment, Healthcare Assistants are involved in teaching basic, specialized, and technical tasks to nursing students.

- Healthcare Assistants reported taking on the teaching responsibilities either in response to directives from registered staff or due to their close working relationship with students.

- Participants justified their involvement through their relationship with patients and students and because of mentor unavailability.

\section{Implications for practice and/or policy}

- The lack of clear role boundaries between registered and unregistered staff provides an avenue for role overlap, role conflict, and role confusion to occur in practice.

- Whilst Healthcare Assistants may feel confident in being involved, in the teaching and learning process of student nurses there are outstanding questions around knowledge and role expectations.

\section{Conclusion}

This study has confirmed that HCAs are playing an active role in student nurse's clinical learning which concurs with the existing UK evidence in the field. In addition, the findings have provided new insights into the relationships between HCAs and students, their role in teaching and why this is occurring. Despite having no preparation for this extension of their role, HCAs in this study claim they are teaching a range of specialized, technical, and patient care tasks with and without the supervision of RNs. However, HCA involvement in student learning has wide spread consequences. On the one hand, HCAs may be well-placed to provide students with the opportunity to further develop skills and competencies; however, the expanding role of the HCA has the potential to alter future patterns of student nurse learning and work. It is recommended that further research in this area be undertaken to explore the extent and impact on student nurse learning experience.

\section{Funding}

This research received no specific grant from any funding agency in the public, commercial, or not-for-profit sectors.

\section{Conflict of interest}

No conflict of interest has been declared by the authors.

\section{Author contributions}

All authors meet at least one of the following criteria (recommended by the ICMJE: http://www.icmje.org/ethical_1author. html) and have agreed on the final version:

- substantial contributions to conception and design, acquisition of data, or analysis and interpretation of data.

- drafting the article or revising it critically for important intellectual content.

\section{References}

Allan H.T. \& Smith P.A. (2009) How student nurses' supernumerary status affects the way they think about nursing. Nursing Times 105(43), 10-13.

Allan H.T., Smith P., Lorentzon M., O’Driscoll M. \& Pope R. (2008) Leadership for Learning. Final report. Centre for research in Nursing and Midwifery education, Faculty of Health and Medical Sciences, University of Surrey, Surrey.

American Nurses Association (2007) Position Statement on Utilisation of Nursing Assistive Personal in All Settings. American Nurses Association, Washington, DC.

Arborio A.M. (2004) Climbing invisible ladders: How nurse's aides craft lateral careers. Ethnography 5(1), 75-105.

Bach S., Kessler I. \& Heron P. (2005) Nursing a Grievance? The Role of Health Care Assistants in a Modernised NHS. British Academy of Management Conference; 13-15 September 2005. Said Business School, University of Oxford, Oxford

Behrens H. (2003) NVQs reliable indicators of competence? Nursing Older People 14(3), 33. 
Blumer H. (1969) Symbolic Interactionism: Perspective and Method. Prentice-Hall, Englewood Cliffs, NJ, USA.

Bridges J., Meyer J., Glynn M., Bentley J. \& Reeves S. (2003) Inter-professional care coordinators: the benefits and tensions associated with a new role in UK acute health care. International Journal of Nursing Studies 40(6), 599-607.

Burkey B.P. (1984) Student Nurses' Perceptions of Training. University of Manchester, Manchester.

Butler-Williams C., James J., Cox H. \& Hunt H. (2010) The hidden contribution of the Health Care Assistant: a survey-based exploration of support to their role in caring for the acutely ill patient in the general ward setting. Journal of Nursing Management 18, 789-795.

Cahill H.A. (1996) A qualitative analysis of student nurses' experience in mentorship. Advanced Journal of Nursing 24(4), 791-799.

Cowie H., Smith P. \& Lorentzon M. (2008) Leadership for Learning: A Literature Study of Leadership for Learning in Clinical Practice. University of Surrey, Faculty of Health and Medical Sciences, Division of Health and Social Care, Surrey.

Creek S. (2003) Students, HCAs and the very inspirational Ms Gibbs. Letters. Nursing Times 99(38), 14.

Dahle R. (2003) Shifting boundaries and negotiations on knowledge: interprofessioal conflicts between nurses and nursing assistants in Norway. International Journal of Sociology and Social Policy 23(4/5), 139-158.

Department of Health (2004) Agenda for Change Final Agreement. Department of Health, London.

Donaldson J. \& Catrer D. (2005) The value of role modeling: perceptions of undergraduate and diploma nursing (adult) students. Nurse Education in Practice 5, 353-359.

Duffin C. (2001) HCA task on more nursing tasks. Nursing Standard 16(5), 9.

Gerrish K. \& Lacey A. (eds) (2010) The Research Process in Nursing, 6th edn. Wiley- Blackwell, London.

Gibbs H. (2003) A guide to surviving your student years. Student Special. Nursing Times 99(36), 38-39.

Glen S. \& Clark A. (1999) Nurse education: a skill mix for the future. Nurse Education Today 19, 12-19.

Gray M. \& Smith L.N. (1999) The professional socialization of Diploma of Higher Education in Nursing Students (Project 2000): a longitudinal qualitative study. Journal of Advanced Nursing 29(3), 639-647.

Hancock H. \& Campbell S. (2006) Developing the role of the healthcare assistant. Nursing Standard 20(49), 35-41.

Hancock H., Campbell S., Ramprogus V. \& Kilgour J. (2005) Role development in Health Care Assistants: the impact of education on practice. Journal of Evaluation in Clinical Practice 11(5), 489-498.

Hand T. (2012) Regulation of Health Care Support Workers: An Overview. Royal College of Nursing, London.

Harrison S. (2006) The march of the mentors. Nursing Standard 20(27), 14-15.

Higgins A. \& McCarthy M. (2005) Psychiatric nursing students' experience of having a mentor during their first practice placement: an Irish perspective. Nurse Education in Practice 5, 218-224.

Institute of Medicine (2010) Committee on the Robert Wood Johnson Foundation Initiative on the Future of Nursing, at the
Institute of Medicine. A Summary of the February 2010 Forum on the Future of Nursing: Education. National Academies Press, Washington DC. 2010. Retrieved from http://www.nap.edu/ catalog.php?record_id=12894 on 21 January 2011.

Kessler I., Heron P. \& Dopson S. (2008) Professionals and Assistants in the British Health Service: Friends or Foes?. Personnel Policies Study Group European group of Public Administration Conference, Erasmus University, Rotterdam, Netherlands (3-6th Sept 2008).

Kessler I., Heron P., Dopson S., Magee H. \& Swain D. (2010) Nature and Consequences of Support Workers in a Hospital Setting. Final report. NIHR Service Delivery and Organisation programme. Retrieved from http://www.sdo.nihr.ac.uk/ projdetails.php?ref=08-1619-155 on 20 October 2011.

Kirk R. \& Keynes M. (2003) Students should make the most of HCAs on placements. Letters Nursing Times 99(41), 14.

Knibbs W., Smith P., Magnusson C. \& Bryan K. (2006) The Contribution of Assistants to Nursing. Final report for the Royal College of Nursing. Healthcare Workforce Research Centre, University of Surrey, Surrey.

Lee-Treweek G. (2003) Women, Resistance and Care: An Ethnography of Nursing Auxiliary Work'. In The Cultural Study of Work (Harper D., Lawson H., eds), Rowman and Littlefield, Lanham, US.

Lincoln Y.S. \& Guba G.E. (1985) Naturalistic Inquiry. Sage Publications, Newbury Park, London.

Lloyd-Jones M., Walters S. \& Akehurst R. (2001) The implications of contact with the mentor for preregistration nursing and midwifery. Journal of Advanced Nursing 35(2), 151-160.

Mackintosh C. (2006) Caring, the socialisation of pre-registration student nurses, a longitudinal study. International Journal of Nursing Studies 43(8), 953-962.

McGowan B. (2004) A Realistic Evaluation of Undergraduate Perceptions of the Definition, Operationalisation and Effect of Supernumerary Status. Research Report. University of Ulster, Northern Ireland.

McGowan B. (2006) Who do they think they are? Undergraduate perceptions of the definition of supernumerary status and how it works in practice. Journal of Clinical Nursing 15, 1099-1105.

McKenna H.P., Hasson F. \& Keeney S. (2004) Patient safety and quality of care: the role of the Health Care Assistant. Journal of Nursing Management 2(6), 452-459.

Mead G.H. (1934) Mind, Self and Society. University of Chicago Press, Chicago.

Melia K.M. (1981) Student Nurses' Accounts of Their Work and Training: a Qualitative Analysis. Unpublished $\mathrm{PhD}$ Thesis, University of Edinburgh, Edinburgh.

Miles M.B. \& Huberman A.M. (1994) Qualitative Data Analysis: An Expanded Sourcebook, 2nd edn. Sage Publications, California.

Mulholland H. (2003) Survey of Nursing Students reveals bleak training picture. Nursing Times 99(36), 2.

National Guidance Research Forum (2006) Health Occupations. Retrieved from http://www.guidance-research.org/future-trends/ health/occupations on 28 October 2011.

Neary M., Phillips R. \& Davies B. (1996) The introduction of mentorship to Project 2000 in Wales. Nursing Standard 10(25), 37-39. 
Nursing and Midwifery Council (2004) Consultation on a Standard to Support Learning and Assessment in Practice. Nursing and Midwifery Council, London.

Nursing and Midwifery Council (2010) Standards of Proficiency for Pre-registration Nursing Education. Nursing and Midwifery Council, London.

O’Connor S.J. (2007) Developing professional habitués: a Bernsteinian analysis of the modern nurse apprenticeship. Nurse Education Today 27(7), 748-754.

O’Driscoll M.F., Allan H.T. \& Smith P.A. (2010) Still looking for leadership - who is responsible for student nurses' learning in practice? Nurse Education Today 30(3), 212-217.

Ousey K. (2006) Being a Real Nurse. Paper presented at RCN International Research Conference York, UK.

Ousey K. (2009) Socialisation of student nurses- the role of the mentor. Learning in Health \& Social Care 8(3), 175-184.

Patton M.Q. (1987) How to Use Qualitative Methods in Evaluation. Sage Publications, Newbury Park.

Pearcey P. (2000) Role perceptions of auxiliary nurses: An exploratory study. Journal of Research in Nursing 5(1), 5563.

Pearcey P. (2008) Shifting Roles in Nursing - Does Role Extension Require Role Abdication? Journal of Clinical Nursing 17, 13201326.

Polit D.F. \& Hungler B.P. (1999) Nursing Research: Principles and Methods, 6th edn. Lippincott, Philadelphia.

Pond C. (2012) Support Workforce Skills Strategy. Skills for Health, UK.

Slaughter S. (2007) Standards must be maintained. Letter of the month. British Journal of Healthcare Assistants 1(6), 256.

Spilsbury K. \& Meyer J. (2004) Use, misuse and non-use of Health Care Assistants: understanding the work of Health Care Assistants in a hospital setting. Journal of Nursing Management 12(6), 411-418.

Spilsbury K. \& Meyer J. (2005) Making claims on nursing work: exploring the work of healthcare assistants and the implications for Registered Nurses' role. Journal of Research in Nursing 10 (1), 65-93.

Spilsbury K., Studdard L., Adamson J., Atkin K., Borglin G., McCaughan D., McKenna H., Wakefield A. \& Carr-Hill R.
(2009) Mapping the introduction of assistant practitioner roles in acute NHS (Hospital) trusts in England. Journal of Nursing Management 17, 615-626.

Thornley C. (1997) The Invisible Workers: An Investigation into the Pay and Employment of Healthcare Assistants in the NHS. Unison, London.

Thornley C. (1998) Cheap and Flexible: Perspectives on low pay, local pay and efficiency for NHS Health Care Assistants. Paper presented at the BUIRA Conference, University of Keele, July, in nurses and Health Care Assistants in the NHS', Sociology of Health o Illness 22(3), 349-363.

Thornley C. (2000) A question of competence? Re-evaluating the roles of the nursing auxiliary and Health Care Assistant in the NHS. Journal of Clinical Nursing 9(3), 451-458.

Tod A. (2006) Interviewing. In The Research Process in Nursing (Gerrish K., Lacey A., eds), Blackwell Publishing Ltd, Oxford.

Unison (2008) Healthcare Assistant Survey. Unison, London.

Unison (2010) Dedicated to Healthcare HCA Survey Results 2010. Unison, London. Retrieved from http://www.unison.org.uk/ acrobat/19489.pdf on 8 July 2011.

United Kingdom Central Council (1999) Fitness for Practice. (The Peach report) The UKCC Commission for Nursing and Midwifery Education, UKCC, London.

Wakefield A., Spilsbury K., Atkin K., McKenna H., Borglin G. \& Stuttard L. (2009) Assistant or substitute: Exploring the fit between national policy vision and local practice realities of assistant practitioner job descriptions. Health Policy 90(2), 286295.

Waters A. (1999) HCAs can help train nurses. Nursing Standard 13(19), 7.

Workman B.A. (1996) An investigation into how the Health Care Assistants perceive their own role as 'support workers' to qualified staff. Journal of Advanced Nursing 23(3), 612-619.

Wright K. (2006) The role of health-care assistants in supporting student nurses. Nursing and Residential Care 8(10), 35-36.

Wurstner J. \& Koch F. (1995) Role redesign in Perioperative Settings. AORN Journal 61(5), 834-844.

Yellott G. (2003) The role of the Health Care Assistant (HCA) in supporting student nurses. Mentor's Newsletter, The University of Nottingham Issue 5, September. 
The Journal of Advanced Nursing (JAN) is an international, peer-reviewed, scientific journal. JAN contributes to the advancement of evidence-based nursing, midwifery and health care by disseminating high quality research and scholarship of contemporary relevance and with potential to advance knowledge for practice, education, management or policy. JAN publishes research reviews, original research reports and methodological and theoretical papers.

For further information, please visit JAN on the Wiley Online Library website: www.wileyonlinelibrary.com/journal/jan

$\underline{\text { Reasons to publish your work in } J A N \text { : }}$

- High-impact forum: the world's most cited nursing journal, with an Impact Factor of 1.477 - ranked 11th of 95 in the 2011 ISI Journal Citation Reports (Social Science - Nursing).

- Most read nursing journal in the world: over 3 million articles downloaded online per year and accessible in over 10,000 libraries worldwide (including over 3,500 in developing countries with free or low cost access).

- Fast and easy online submission: online submission at http://mc.manuscriptcentral.com/jan.

- Positive publishing experience: rapid double-blind peer review with constructive feedback.

- Rapid online publication in five weeks: average time from final manuscript arriving in production to online publication.

- Online Open: the option to pay to make your article freely and openly accessible to non-subscribers upon publication on Wiley Online Library, as well as the option to deposit the article in your own or your funding agency's preferred archive (e.g. PubMed). 